\title{
Breast Screening in Germany
}

\author{
Sylvia H. Heywang-Köbrunner \\ Referenzzentrum Mammographie München, Germany
}

Key Words

Mammography screening · Health care system

\section{Summary}

Based on the data of large randomized studies, on data and experience from other, mainly European countries, where structured service screening has meanwhile been offered for many years, and on extensive reconsiderations of advantages and risks, in 2002 the German parliament had decided to introduce service screening in Germany. Meanwhile strict regulations have been issued for a comprehensive screening program. The goal of the program is to assure high quality of technique and of diagnosis, as well as adequate further assessment and treatment of screening-detected lesions to warrant both high rate of detection and a minimum of potential side effects. Such side effects could e.g. occur with a too high rate of false alarm or with inadequate surgical biopsies of discrete changes that eventually proved to be benign. For this purpose the program strictly follows the 'European Guidelines for Quality Assurance in Mammography Screening and Diagnosis'. Significant educational demands and structural changes are imposed on doctors and personnel who want to participate in the program. The changes and their indicated goals are described and explained. The program, which is associated with fundamental alterations within our health system, is presently starting in Germany. The demanded strict documentation will allow close monitoring of the results, which will be evaluated.

\section{Schlüsselwörter \\ Mammographiescreening · Gesundheitssystem}

\section{Zusammenfassung}

Basierend auf den großen randomisierten Studien, auf den Erfahrungen anderer, vorwiegend europäischer Länder, in denen strukturierte Screeningprogramme bereits seit vielen Jahren angeboten werden, und nach umfassender Reanalyse von Vorteilen und eventuellen Risiken hatte der Bundestag im Jahr 2002 beschlossen, in Deutschland ein strukturiertes Screeningprogramm einzuführen. Inzwischen wurden hierfür strenge Regularien mit Gesetzescharakter geschaffen. Ziel des Programmes ist es, eine hohe Qualität der Mammographietechnik und Diagnose im Screening zu sichern, ebenso wie eine angemessene weitere Abklärung und Behandlung der im Screening entdeckten Veränderungen, um sowohl eine hohe Entdeckungsrate als auch eine Minimierung möglicher Nebenwirkungen zu garantieren. Letztere können z.B. durch eine zu hohe Rate an falschem Alarm oder durch regelmäßige operative Klärung kleiner, nur im Screening entdeckter und schließlich gutartiger Veränderungen vorkommen. Das Programm folgt daher streng den «Europäischen Leitlinien für die Qualitätssicherung des Mammographie-Screenings". Umfassende Anforderungen an Schulungen und strukturelle Veränderungen werden Ärzten und nichtärztlichem Personal, die am Screeningprogramm teilnehmen wollen, auferlegt. Die Änderungen und die betreffenden Ziele werden beschrieben und erklärt. Das Programm, das mit fundamentalen Änderungen in unserem Gesundheitssystem verbunden ist, startet derzeit in Deutschland. Die geforderte strenge Dokumentation erlaubt eine engmaschige Überwachung der Ergebnisse, die evaluiert werden.

\begin{tabular}{ll}
\hline KARGER & ๑ 2007 S. Karger GmbH, Freiburg \\
Fax +49 7614520714 & Accessible online at: \\
$\begin{array}{l}\text { E-mail Information@Karger.de } \\
\text { www.karger.com }\end{array}$ & www.karger.com/brc
\end{tabular}

Prof. Dr. Sylvia H. Heywang-Köbrunner Referenzzentrum Mammographie München Einsteinstr. 3

81675 München, Germany

Tel. +49 89961661330

E-mail heywangkoe@lrz.tum.de 


\section{Introduction}

Breast cancer is the most frequent malignancy in women. Statistically $30-40 \%$ of women with breast cancer die of the disease. Mortality correlates with biological factors, but shows an almost linear correlation with lesion size at detection. So early detection should be one of the most important goals to save women from dying of breast cancer.

Ample data, proven at the highest scientific level of evidence, show that mammography screening allows to reduce breast cancer mortality by approximately $30 \%$. As mentioned by Ingvar Andersson in the editorial of this issue [1] breast screening and mammography also have limitations and even potential disadvantages. Advantages and limitations have internationally and particularly in Europe been thoroughly investigated. Based on this knowledge European guidelines for quality assurance have been developed, and it is recommended that breast screening be performed only in highly quality-assured and wellmonitored breast screening programs [2]. The program serves to warrant that the possible advantages are achieved, while potential disadvantages are minimized. The program demands extensive documentation to continuously monitor the quality and counteract when weaknesses are detected.

Using this knowledge most highly developed countries have decided to establish breast screening programs, and in Germany parliament has decided to establish a breast screening program for women aged 50-69. In 2003-2004 regulations were made by a committee consisting of the 'Kassenärztliche Bundesvereinigung' and the German Insurances, which are fundamental to the allowance to perform any screening in Germany [3-6].

The regulations follow the 'European Guidelines for Quality Assurance in Mammography Screening and Diagnosis' quite strictly and sometimes even exceed the demands.

The regulations include prerequisites for

- technical quality assurance

- training of all the involved personnel

- responsibilities and structure of each regional program

- participation of practices or institutions, technologists, readers (radiologists or gynecologists with permission to perform/read mammograms), pathologists, surgeons or gynecologists responsible for further treatment

- invitation of women for screening

- the screening process

- assessment

- documentation and evaluation.

This publication attempts to give an overview of the recommendations, which include about 200 pages of regulations, and to make the goals of this program understandable to physicians and those interested in the program, who are not directly involved.

Overall, the regulations are mandatory. No screening and no other program is allowed for early detection of breast cancer in asymptomatic women aged 50-69 unless these regulations are fulfilled.

\section{The Program}

\section{Its Institutions and Structure}

The program is put into reality by an institution called 'Kooperationsgemeinschaft Mammographie'. The 'Kooperationsgemeinschaft Mammographie' is responsible to the 'Kassenärztliche Bundesvereinigung' (a central organ which represents doctors in private practice and which is responsible for quality assurance in this sector of the German Health System). The 'Kooperationsgemeinschaft Mammographie' is responsible for additional regulations, for interpretation of the regulations, for all certifications and recertifications.

The 'Kooperationsgemeinschaft Mammographie' is supported by 5 Reference Centers, which are responsible to offer training courses and offer possibilities for secondment to technologists and doctors involved in the program. The reference centers have to support the 'Kooperationsgemeinschaft Mammographie' to assure high quality in the regions which are assigned to each center, to counsel the doctors and their involved personnel, to document and evaluate the program. Finally, the reference centers are also expected to perform scientific evaluations to optimize and improve the program.

Germany is split up into approximately 100 regions, and it has been decided that one or two doctors have to be responsible for the program in each of the regions. The responsibilities include medical and organizational issues for the whole program in that area.

\section{Technical Quality Assurance}

The technical quality assurance also follows the European guidelines. It includes yearly, monthly, weekly and daily tests, the results of which have to be within strict limits before mammograms may be performed. Parts of these tests are made on a daily basis on each mammography unit in the system. The values are transmitted through a protected Internet connection to the reference center in charge, where they are checked in part automatically, in part directly by the physicist, who has to give initial support and consider possible measures to overcome a problem, if present. If a significant deviation occurs, for example on a daily test, mammograms may not be taken on that mammography unit until the problem is solved.

The regulations initially only included conventional film screen mammography. Meanwhile an addendum has been issued regulating quality assurance for digital mammography. Adaptations were made by the responsible committees to adapt the regulations to the pre-existing German law and to the standardized phantoms which are in use in Germany. So, small differences do exist. Their importance is presently still being discussed. 
Any personnel that is involved has to participate in multiple training courses on breast screening, on technique, quality assurance, on interdisciplinary breast diagnosis reaching from screening to assessment to histopathology, to treatment and psychological aspects. Readers have to attend courses on reading screening mammograms. Doctors responsible for a region in addition have to attend courses on reading mammograms, on breast ultrasound, on percutaneous breast biopsy, and on organization. Most courses last 2-3 days.

All technologists have to participate in a 3-day course and have to attend a secondment of 2 weeks at a reference center. All readers have to attend one-week secondments at a reference center; responsible doctors have to perform even 4-week secondments. Pathologists have to participate in training courses on histopathology of small screening-detected lesion, in order to obtain the allowance to participate in the program. So, overall a high level of education is demanded for the program, and doctors and technologists who want to participate have to leave their work for the time required and attend courses and secondments.

\section{Responsibilities and Structure of the Regional Programs}

As mentioned, Germany has been split up into approximately 100 screening regions. Doctors interested in leading a program could apply and have then been selected. These doctors have very high responsibilities, since they have to choose their readers, their technologists, and have to check the quality and training of the involved personnel. They have to organize the independent double reading of all cases in their region and the consensus reading of all suspicious or discrepant cases. They have to perform all imaging assessment and all core needle biopsies on screening patients of their screening region themselves. They may perform stereotactic biopsies or assign one responsible partner. They have to organize pre- and postoperative conferences on all cases requiring histopathologic assessment, have to warrant timely diagnoses and assessment, and have to assure complete documentation even for those patients who leave the program for surgery outside the program.

Besides medical responsibility, they are responsible for organization (information of the screened women, recall of all women with suspicious findings; timely reporting and assessment including management of personnel and potential shortage of personnel etc.), economic aspects, and they are legally responsible. The latter aspect has been quite difficult also in terms of insurance, which issue, however, meanwhile seems to be mostly solved.

\section{Prerequisites for the Participating Institutions and Their Technologists}

Doctors and medical personnel have to fulfill the above training requirements before they are eligible to work in the program. The involved institutions or private practices need to warrant complete separation of diagnostic and screening mammography. That is, both need to take place either in different locations or have to be separated using different time slots. It is demanded that participating units have to exclusively offer screening on 3 full days, which measure obviously was chosen to warrant high throughput by dedicated personnel only.

The separation of screening from diagnostic mammography was argued to be necessary to create an atmosphere of prevention instead of fear in women screened (fear by meeting other women with a positive finding or known breast cancer). The regulation also has the effect that screening mammography is limited to a small number of institutions with high throughput.

All allowances and certifications are decided by the 'Kooperationsgemeinschaft Mammographie'. Reference centers have to give support by counselling the responsible doctors and officials.

In order to assure correct fulfillment of the requirements, usually contracts are needed between the doctors and practices who are involved in the program. If a responsible doctor cannot find cooperating institutions/partners who will support him/her to cover the complete area, it is his responsibility to organize screening in busses, so-called 'mammobiles', which have to drive to the villages or cities where screening is not offered to women.

\section{Prerequisites for Participating Readers}

The responsible doctor has to choose his readers, check their training and, in the long run, their accuracy. He is responsible that each reader reads at least mammograms of 5,000 women per year. This implies that depending on the participation rate in the region the number of readers is limited. For example, if 15,000 women - corresponding to a participation rate of approximately $40 \%$ - participate, 6 readers (including the responsible doctor who has to fulfill the same requirements) can be included at most. Readers reading lower numbers of mammograms risk to lose their permission. All readers need to take yearly tests. In these tests readers with lower performance are excluded.

\section{Prerequisites for Responsible Doctors}

The responsible doctor needs to undergo more extensive training than the readers (see above), take the same tests, and assure that the prescribed logistics and quality parameters be reached in his region. Also the responsible doctor has the duty 
to assure that his readers can read $\geq 5,000$ mammograms per year and that all the other regulations, rules, and quality parameters are achieved.

In Germany there is a law indicating that examinations which can be performed outside hospitals (like mammography or mammography screening) should be performed outside hospitals. Allowance for participation of doctors in the system is usually only given if the tasks (e.g. in a certain region) cannot be fulfilled by doctors/institutions in private practice (e.g. due to a lack of personnel or equipment). The law is unique and fundamental to the German Health System and has existed before initiation of the screening program.

\section{Invitation of Women for Screening}

Women are invited to screening based on the inhabitants' registries in Germany by an independent institution, the so-called 'Zentrale Stelle'. Thus the invitation is strictly population based. Women are invited at a certain date and time and to a fixed place. Women can change the time of the appointment, choose a different screening unit - provided the screening unit belongs to the indicated certified units - and a woman can also cancel the date, if she does not want to be screened. The examination and assessment is free for the women.

\section{The Screening Process}

Each mammogram is double read by at least two independent readers. Breast density and mammographic diagnoses are made using a reduced BI-RADS classification: 1 = normal; 2 = benign finding versus $4=$ recall (these patients undergo imaging and/or histopathologic assessment). BI-RADS 5 means very high suspicion or almost certain imaging diagnosis of breast cancer. BI-RADS categories 4 or 5 are considered positive findings. BI-RADS 1 and 2 are considered a negative finding (with the recommendation to go 'back to screening '). All diagnoses and all other information are entered online into the computer network.

First and second readers are blinded to the reading of the other reader and to clinical information. If at least one of the two readers reports a positive finding, the case is discussed in the so-called consensus conference. The process of double reading and selection of discrepant or suspicious cases is software supported. The consensus conference is held by the responsible doctor(s) and by the involved readers. If in a consensus conference further assessment is considered necessary, the patient is recalled for further assessment; if no assessment is considered necessary, the patient is informed about a benign result and goes back to screening.

Adequate information and recall of all patients with a suspicion of breast cancer without exception belongs to the tasks of the responsible doctor.

\section{Assessment of Suspicious Findings in the Program}

Assessment has to be performed by the doctors responsible for the regional programs. The assessment follows the European guidelines and the international recommendations.

That is, first imaging (preferentially additional mammographic views, magnification views or ultrasound) is used to exclude malignancy. If this is not possible, the next step should be whenever feasible - a needle biopsy. Needle biopsy includes sonographically or stereotactically guided core needle biopsy. Vacuum-assisted breast biopsy can be performed. However, payment is not yet sufficiently solved. Following the European guidelines it should be attempted that cancers be diagnosed by needle biopsy instead of surgical biopsy in more than $70 \%$ of the cases (optimally $>90 \%$ ). Histology is systematically double read by one experienced pathologist, associated to or within the reference center. Any histopathological assessment has to be followed by an interdisciplinary conference to assure representative removal and agreement of the results, a process which has proven to be essential for achieving reliable diagnoses.

Benign findings need to the proven, as well as malignant findings, and the responsible doctor has to follow the cases down to the final diagnosis and the TNM staging.

\section{Documentation and Evaluation}

Every step of the screening process is documented in the SafeNet database, in which doctors can access patient data, when they have access to the patient's screening number by being their treating physician (1st, 2 nd reader, responsible doctor). The database includes the usual patient data, some individual information on breast disease, a small history, very limited clinical data, which are fed into the system by the technologist, technical data of the mammogram, the result of each reading and of the consensus conference. Furthermore, it includes all imaging data of all suspicious lesions and all data from the histopathological assessment (1st and 2nd reading) of lesions, the result of the so-called preoperative conference, by which the results of the histopathological assessment are correlated with histopathology and presented to the operating gynecologist or surgeon, if applicable. In case of malignancy data on surgical and medical further treatment have to be recorded in the electronic software program. All recorded data can no more be changed.

Newer developments will allow to combine the screening database with the database of the cancer registries. Thus the work of the responsible doctor may be significantly improved, since follow-up down to the TNM stage for each cancer case is extremely time-consuming and sometimes difficult for the responsible doctor, if the patient chooses to be operated in another hospital, for example. 


\section{Discussion}

For a new program many questions may be discussed, for example the screening interval or the chosen age group. Of course, further cancers could be detected by extending the program and including shorter intervals. However, for a start it is reasonable to concentrate on the most important age group with the highest medical benefit, the best proven evidences of benefit, and the best cost-effectiveness.

In Germany, where wild screening had been widely used in a decentralized system, many other questions may come up, as this program forces significant changes of the structure. Also, the program does not include clinical examination or other modalities.

The problem to date is that mammography is not perfect. It detects only $80-90 \%$ of the detectable cancers, and interval cancer cannot be avoided.

However, for clinical examination or self-examination no data exist indicating a significant reduction of mortality [7]. For ultrasound several studies on preselected patients demonstrate advantages, mainly when adding it to mammography. However, data on false positives, an important potential harm of screening, vary significantly for breast ultrasound from publication to publication. Quality assurance and operator-dependent accuracy are important issues, which need to be solved first. So far no other nation has yet decided on a large study or even a screening program that integrates palpation or ultrasound. MRI is certainly not appropriate for population-based screening, but is presently tested for highly selected patient groups. So, to date a system for breast screening and quality assurance was established based on the very well monitored European data and its QA system.

Whereas the screening program may not offer all solutions, the German health system offers various possibilities. There exists e.g. a prevention program 'Vorsorge', in which gynecologists can palpate the patient. Both the responsibles for the breast screening program and the gynecologists should cooperate, since palpation can thus be offered to patients who desire it. Also the gynecologist can decide on the need for shorter intervals or additional ultrasound, if a clinical suspicion or risk factors exist.

In the screening program women are not seen by the radiologist. This does make sense when reading is performed by multiple experts. If a doctor sees a patient before the reading has been performed, the final reading has little effect, since the patient acts (and may act in the wrong way) before she knows the definite diagnosis. Our own experiences in a previous program have shown that blinded double reading and third reading allow to increase the rate of detected cancers by at least $14 \%$, while decreasing the number of false positives. If a patient is alarmed by the rumor of a positive finding, our experience has been that she may drop out of the program and require surgery, which often may be surgery on eventually benign changes.

Avoidance of a contact between doctor and patient before a final diagnosis with an optimum accuracy is available makes sense.

The program forces high throughput, centralization, and concentration on fewer technologists, mammography sites and readers by significant changes in the existing structure. The structural changes prove to be tough and sometimes difficult to understand. Expertise is not only expected by high throughput but also by good training and continuous feedback. The program addresses both. The feedback is warranted by the demand for assessment by the responsible doctor and the demand for consensus and multidisciplinary conferences. Other issues could be discussed, as well. However, experience with the program will show its effect and possible weaknesses. Due to the transparent documentation it will be possible to recognize problems and to counteract. Thus, in Germany it will certainly be necessary to build up the demanded quality assurance of this program and follow the set regulations. The results have to be observed and evaluated in order to hopefully further optimize the system and guarantee the advantages of breast screening at an acceptable rate of unavoidable risks.

\section{References}

1 Andersson I: Breast cancer screening with mammography. Breast Care 2007:2: 4-5.

2 EUREF European Guidelines for Quality Assurance in Mammography Screening and Diagnosis. European Commission, Luxembourg, 2006.

3 Bundesmantelvertrag-Ärzte (BMV-Ä) über besondere Versorgungsaufträge im Rahmen des Programms zur Früherkennung von Brustkrebs durch Mammographiescreening vom 12.12.2003.
4 Änderung der Richtlinien des Bundesausschusses der Ärzte und Krankenkassen über die Früherkennung von Krebserkrankungen vom 15.12.2003, in Kraft getreten zum 1.1.2004

5 Kassenärztliche Bundesvereinigung: Einführung eines bundesweiten Mammographie-ScreeningProgramms. Beilage zu Dtsch Ärztebl 2004;A(4): $1-3$.
6 Programmrichtlinien. http://www.kooperationsgemeinschaft-mammographie.de/home/home.php. 7 Schulz KD, Albert US (Hrsg): Stufe-3-Leitlinie Brustkrebsfrüherkennung in Deutschland. München, Zuckschwerdt, 2003. 